\title{
Understanding Intention to Explore Business Intelligence Systems: The Role of Fit and Engagement
}

\author{
Junyi Yang \\ McGill University \\ junyi.yang@mail.mcgill.ca
}

\author{
Alain Pinsonneault \\ McGill University \\ alain.pinsonneault@mcgill.ca
}

\author{
J.J. Po-An Hsieh \\ Georgia State University \\ jjhsieh@gsu.edu
}

\begin{abstract}
This paper explores how user engagement affects users' intention to explore business intelligence system (BIS) and how user engagement is promoted by the cognitive fit between BIS interface and tasks and the regulatory compatibility between BIS interface and personal characteristics, such as style of information processing. Results from the lab experiment suggest that the cognitive fit and the regulatory compatibility could both influence users' engagement experience, which in turn affected users' intention to explore BIS. This study may contribute to the extant information systems (IS) literature by uncovering the impacts of engagement experience on intention to explore and responding to the call for investigation of the BIS context where rich visualizations of the systems influence users' engagement experience.
\end{abstract}

\section{Introduction}

Business intelligence system (BIS) and its related areas have obtained increasing importance in the past two decades [15]. BIS is a type of data-driven technology that can extract, convert, analyze, visualize, and present large data sets to assist strategic planning and managerial decision making [20], and has been rated as one of the top 10 strategic technologies [26]. According to a survey of the state of business analytics by Bloomberg Businessweek [8], 97 percent of organizations whose revenues surplus $\$ 100$ million use BIS to some extent. BIS handles large amount of unstructured data, supports a wide range of business decisions from operational to strategic, and helps identify new strategic business opportunities [66]. Therefore, organizations devote substantial resources to implementing BIS [17, 53, 59]. Different features in BIS provide access to different types of information and different ways of analyzing and making sense of the information. While BIS provides a myriad of features, it is the user's responsibility to use them and explore them. Given the flexibility and enriched functionality of BIS, users who apply BIS in an explorative approach are more likely to use a broader scope of system features to support their work and develop capacity for better work performance [2, 56, 65]. Therefore, we focus on the exploration of BIS in this study, specifically users' intention to explore BIS which determines exploration behaviors [56].

Intention to explore refers to users' willingness and purpose to explore a new technology and find potential approaches to use a technology in their work [56, 58]. Extant studies on antecedents of intention to explore mainly examined firm-specific information technology (IT) knowledge [e.g., 58], behavioral, normative and control beliefs [e.g., 71], and team empowerment [e.g., 56]. While these studies have provided insights into different aspects related to user exploration, the extant research does not provide insights on how user experience of IS influences intention to exploration. Specifically, the human-computer interaction studies have emphasized the need to understand the engaging experiences of interacting with IS [e.g., 31]. User engagement promotes sales of an e-commerce site, transmission of information from an online forum, and users' interest in multimedia presentation [60]. Despite these positive outcomes of user engagement, there is limited understanding on how user engagement contributes to intention to explore. Thus, our first research question pertains to how user engagement influences users' intention to explore BIS. In the general work context, the idea of a "fit" between a person and a job affects the engagement experience [e.g., 13, 14]. Similarly, in the BIS context, the fit between BIS interface and tasks and the fit between BIS interface and users may lead to an engagement experience. Hence, our second research question involves how the fit between BIS interface and tasks and the fit between BIS interface and users affect user engagement, respectively.

The remainder of the paper is organized as follows. In section two, we introduce the theoretical 
background of our study. In section three, we develop a framework for linking concepts of fit, engagement and intention to explore and present the hypotheses of the paper. Section four describes the research method while section five presents the results. In section six, we discuss the results and present the implications. Section seven provides concluding remarks.

\section{Theoretical background}

\subsection{Conceptualizations of engagement in the IS use context}

In general work context, engagement is defined as a psychological state in which people feel dedicated and energetic towards their job [5]. Work engagement represents a positive and fulfilling state of well-being that is contrast to job burnout [5]. Engaged employees are energetic and actively involved in their work [6]. Besides its essential roles in general work context, engagement is also considered as a desirable user response to computermediated activities in the context of human computer interaction [50]. Users describe their engaging experiences of interacting with IS as feelings that the system has caught, captured, and captivated their interest [39]. Users are engaged in a system when it "holds their attention and they are attracted to it for intrinsic rewards" [39, p. 58]. For instance, multimedia presentations designed for educational purpose should engage their audiences [69]. Online retailers are providing interactive website features to engage their customers and encourage their purchasing behaviors [30]. Engagement is an essential and appealing experience sought after by both users and IS developers.

When interacting with IS, an engaging experience involves the sensory appeal of the system, the level of affective involvement, and the challenge users received from system utilization [60]. The sensory appeal of IS can be represented by aesthetic experiences [50, 61]. Aesthetics refers to the visual appearance of an interface that conforms to design principles (i.e., symmetry, balance, emphasis, harmony, proportion, rhythm, and unity) [7]. Users' perception of aesthetics consists of two dimensions: classic aesthetics that emphasizes orderly and clear design and relates to many of the design rules, and expressive aesthetics that pertains to the creativity and originality of a design [51]. The level of affective involvement can be manifested by perceived enjoyment, which refers to the extent to which the activity of using IS is perceived to be enjoyable in its own, apart from any performance consequences that may be anticipated [18]. Perceived enjoyment can be characterized as an intrinsic motivation derived from the interaction with the system [10]. The challenge users receive from the system can be manifested by cognitive effort, which leads to challenging and demanding feelings as effort associated with using IS increases [25]. Cognitive effort refers to the psychological costs of performing the task of obtaining and processing the relevant information in order to arrive at one's decision [63]. A consistent finding is that humans have limited cognitive resources and allocate them cautiously [e.g., 62, 67]. Cognitive effort is conceived as costly and humans expend only the effort necessary to make a satisfactory rather than optimal decision. For instance, in the context of decision support system, decision makers aim to maximize decision quality and minimize effort [73].

\subsection{Antecedents of engagement}

In the general work context, job demands and job resources are related to engagement [4]. For instance, professional skills promote work engagement when the workload is high, and mitigates the negative effect of high workload on work engagement. The idea of a "fit" between a person and a job also affects the engagement experience. Person-job fit can be conceptualized as the fit between an individual's knowledge, skills, and abilities, and the demands of the job [e.g., 14] or the fit between the needs and desires of an individual and what is provided by the job [e.g., 13]. Research has shown that employees who perceive a high level of convergence between their personal characteristics and the requirements of the job experience a high level of job satisfaction [e.g., 11].

People's responses to system interface affect their potential to experience engagement [60]. The cognitive fit, which refers to a match between interface design and tasks [77], has been shown to influence website users' cognitive decision efforts for shopping and their attitude towards the e-commerce website (e.g., the feeling of enjoyment) [33], which are two key aspects of engagement experience. The cognitive fit between query interface and task complexity has been found to influence users' subjective mental workload [72]. Additionally, a regulatory compatibility of personal and environmental factors that are involved in conducting a task or activity may lead to deep involvement and eager task pursuit [47]. It may also result in a positive state of relaxation and quiet [47], a greater willingness to purchase relevant products [3], greater 
persuasion [79], and stronger motivational intensity [23, 64]. Individuals who experience a regulatory compatibility are intrinsically motivated to engage in the activities or tasks [47]. When individuals experience a state of regulatory compatibility, they enjoy the experience of conducting activities [1, 19].

\subsection{Outcomes of engagement}

In the work context, engaged employees find their work more enjoyable, and thus turn this enjoyment into effective actions. Engaged employees tend to bring their full capacity to solving problems, connecting with people, and developing innovative services [5]. The energy and focus derived from the work engagement allow employees to bring their full potential to the job [27]. This energetic focus enhances the quality of their core work responsibilities, since employees will be more capable and motivated to concentrate on their core job. Further, employees go beyond the core responsibilities of their work and take the initiative to support the organization through mentoring, volunteering, developing new professional skills [5]. Through these extra-role behaviors, employees dynamically adapt to the ever-changing organizational environment and gain competitive advantages. Work engagement is consistent with the broaden-and-build perspective proposed by Fredrickson [24]. Research on cognitive broadening demonstrates that positive emotions (e.g., engagement) increase the cognitive flexibility [35], creativity [32, 36], integration [38], and efficiency of thought [37]. A positive emotion state like engagement can go beyond the general motivating properties of pleasant feelings, and be translated into cognitive processes which open possibilities that people overlook under the condition of pressure or distress.

When users are engaged in interacting with a system, enjoyment makes individuals "underestimate" the difficulty associated with using the system since they simply enjoy the process itself and do not perceive it to be arduous [76]. Individuals who experience pleasure or enjoyment from using IS are more likely to form intentions to use it than others across contexts, including educational settings [18], game-based training [75], home use [34], ecommerce transactions [44], knowledge contribution in e-networks [78], knowledge transfer in IS implementation [48], and open-source software project development [70]. The enjoyable experiences of use effectively drive users' interest, relieve their cognitive burdens, and promote use intentions and behaviors [53]. In the context of e-commerce, cognitive effort is a salient factor affecting consumers' intentions to shop online [41]. When products are complex or consumers have limited knowledge, the purchasing process becomes more challenging, leading to greater negative emotion [25]. Aesthetics experience has been applied by software developers in interface design [51]. Aesthetics has been linked to usability and users' skills and needs $[50,61]$.

\section{Research model and hypotheses}

In this study, we drew on the engagement literature to identify typical concepts that could represent the engagement experience of BIS users, including perceived aesthetics, cognitive effort, and perceived enjoyment. When interacting with a system, the cognitive fit between interface design and tasks may influence the engagement experience (e.g., perceived aesthetics, cognitive effort, and perceived enjoyment), and the regulatory compatibility between interface design and personal characteristic may also affect users' engagement experience (e.g., perceived aesthetics, perceived enjoyment). Given that engagement experience can promote cognitive flexibility and creativity, we suspect that engagement experience could enhance users' intention to explore BIS. Thereby, we developed our research model, as shown in figure 1.

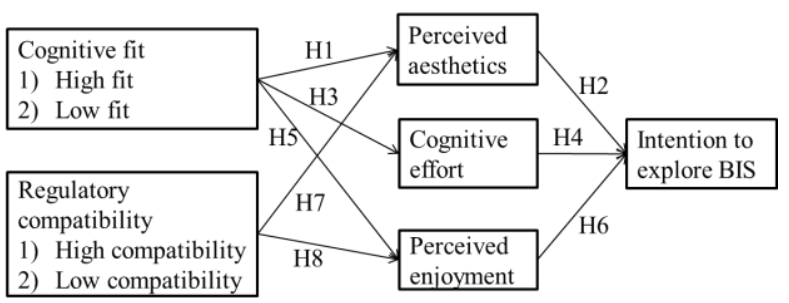

Figure 1. Research model

\subsection{Cognitive fit $\rightarrow$ Perceived aesthetics $\rightarrow$ Intention to explore}

We expect that cognitive fit will be positively associated with perceived aesthetics, which in turn will be positively associated with intention to explore BIS.

Cognitive fit refers to a match between interface design and tasks [77]. When a cognitive fit exits, the information emphasized in the interface facilitates the task solving activity [77]. Thus, when conducting tasks, users may perceive that the BIS interface has a clear design with emphasis on relevant information, 
and thus consider the interface as aesthetic [7, 51]. In addition, when a cognitive fit occurs, users find it simple to solve problems with the provided interface $[72$, 77]. Users' simplicity evaluation of the application of BIS interface positively affects users' considerations of aesthetics [45]. Thus, when users experience a cognitive fit, they are likely to display higher perceived aesthetics. By contrast, when users experience cognitive mismatch, it's more complex to process the information since users need to adjust the cognitive mismatch [33]. Users may perceive that the BIS interface is poorly designed and doesn't emphasize relevant information, thereby consider the BIS interface less aesthetic. Thus, the first hypothesis is proposed as follows.

H1: Users who experience a high cognitive fit will display higher perceived aesthetics than those who experience a low cognitive fit.

Aesthetics corresponds to the orderly, clear, clean and symmetrical design of a system or visual richness, diversity, and complexity of the system [51]. When users perceive an interface as aesthetic, they tend to have a better impression on it [51]. Users feel aroused or the aesthetic system, and are likely to approach to the system [21]. Aesthetic system has the potential to enhance creativity and innovative exploration of the system [22]. In the BIS context, when users consider the BIS interface as aesthetic, they tend to approach the system and find innovative approaches to explore the BIS. Thus, the second hypothesis is formalized as follows:

$\mathrm{H} 2$ : Perceived aesthetics is positively related to users' intention to explore BIS.

\subsection{Cognitive fit $\rightarrow$ Cognitive effort $\rightarrow$ Intention to explore}

We expect that cognitive fit will be negatively associated with cognitive effort, which in turn will be negatively associated with intention to explore BIS.

When users experience a fit between system interface and tasks, the interface presents the information on which their problem solving is based [77]. Prior studies showed that users who experienced a cognitive fit spent less effort to process the task information in the context of query system [e.g., 72] and online shopping [e.g., 33]. However, when users experience a cognitive mismatch between the interface and tasks, the interface presents irrelevant information for the problem solving [77]. Thus, users consume more efforts to accommodate their mental representations to solve the tasks [33]. In the BIS context, when users experience a fit between BIS interface and tasks, they are likely to spend less effort to perform the tasks, since the BIS interface facilitates the problem-solving process with relevant information. On the other hand, when users experience a mismatch between BIS interface and tasks, they may spend more effort to accommodate their mental representations with irrelevant information. Thereby, the third hypothesis is proposed as follows.

H3: Users who experience a high cognitive fit will consume less cognitive effort than those who experience a low cognitive fit

Humans have limited cognitive resources and allocate them cautiously [e.g., 62, 67]. In the ecommerce context, cognitive effort is a salient factor affecting consumers' intentions to shop online [41]. When products are complex or consumers have limited knowledge, the purchasing process becomes more challenging, leading to greater negative emotion [25]. Similarly, in the BIS context, when users perform tasks that are challenging and requiring much cognitive effort, they tend to have negative feelings toward the BIS, and are less willing to use it. Furthermore, due to limited resources of information processing [43, 52], users remain fewer cognitive resources to find novel ways of using the BIS. Since cognitive resources are essential for technology exploration [2], users who spend more cognitive effort to use the BIS are less likely to further explore the BIS. Thus, the fourth hypothesis is formulated as follows.

H4: Cognitive effort is negatively related to users' intention to explore BIS.

\subsection{Cognitive fit $\rightarrow$ Perceived enjoyment $\rightarrow$ Intention to explore}

We expect that cognitive fit will be positively associated with perceived enjoyment, which in turn will be positively associated with intention to explore BIS.

Prior studies on consumer behaviors found that when experiencing a cognitive fit between website interface and tasks (e.g, shopping), consumers will display a more positive attitude toward the website, and consider the interaction with the website as pleasant and joyful [e.g., 33, 44, 49]. The fit between interface presentation and task can facilitate information processing, which has been shown to increase enjoyment in the website setting [74]. 
Similarly, in the BIS context, when the fit between the BIS interface and the tasks occurs, users' information processing is facilitated, and thus they may consider the interaction with the BIS as enjoyable. By contrast, when users experience a mismatch between the BIS interface and the tasks, their information processing is hindered and thus users may experience less enjoyment. Thus, fifth hypothesis is proposed as follows.

H5: Users who experience a high cognitive fit will display higher perceived enjoyment than those who experience a low cognitive fit.

Enjoyment makes users "underestimate" the difficulties associated with using IS, since they enjoy the process of interacting with IS [76]. Enjoyment creates a lower cognitive burden because the users are experiencing pleasure from the IS and are willing to expend more effort $[1,19]$. As cognitive resources are essential for technology exploration [2], users who feel enjoyable for integrating with the BIS are more likely to have enough cognitive resources for exploration, and thus may display higher intention to explore. In addition, perceived enjoyment is a type of positive affect that has been found to promote desire for exploration [46, 54]]. The enjoyment experienced when interacting with BIS contributes to cognitive flexibility that fuels explorative ideas for using the BIS [53]. Thereby, we propose the sixth hypothesis.

H6: Perceived enjoyment is positively related to users' intention to explore BIS.

\subsection{Regulatory compatibility $\rightarrow$ Perceived aesthetics/Perceived enjoyment $\rightarrow$ Intention to explore}

We expect that regulatory compatibility will be positively associated with perceived aesthetics and perceived enjoyment, which in turn will be positively associated with intention to explore BIS.

A regulatory compatibility refers to the match between personal and environmental factors [47]. In the context of our study, we narrow down the environmental factor as the BIS interface, and the personal factor as the users' style of processing, which is an important personal characteristic that influences information processing [16]. When users experience a high regulatory compatibility between the BIS interface (e.g., visual design) and their style of processing (e.g., visual style of processing), they are likely to focus their attention on the interface and appreciate the visual richness of the interface, and thus may perceive the BIS as aesthetic [51] By contrast, when users experience a low regulatory compatibility between BIS interface (e.g., visual design) and their style of processing (e.g., verbal style of processing), they are less likely to appreciate the visual appearance of the BIS interface, and may consider the BIS as unbalanced or inharmonious. Thus, the seventh hypothesis is formulated as follows.

H7: Users who experience a high regulatory compatibility will display higher perceived aesthetics than those who experience a low regulatory compatibility.

Individuals enjoy regulatory compatibility experiences, are willing to spend additional time experiencing a state of regulatory compatibility, and are intrinsically motivated to engage in such behavioral episodes [47]. In the context of BIS, when users experience a compatibility between the BIS interface (e.g., visual design) and their style of processing (e.g., visual style of processing), they tend to consider this experience as enjoyable. In contrast, when a low regulatory compatibility occurs, users are less likely to enjoy the activity and engage in it [57]. Thus, the eighth hypothesis is proposed as follows.

H8: Users who experience a high regulatory compatibility will display higher perceived enjoyment than those who experience a low regulatory compatibility.

\section{Methodology}

A $2 \times 2$ lab experiment was conducted to examine the hypotheses. Subjects were recruited from undergraduate students, and received McDonalds' coupons after completing the experiment. The two independent variables were cognitive fit and regulatory compatibility. The extent of cognitive fit was manipulated by the interaction of the BIS interface and the tasks. All subjects viewed the same BIS interface, but one group of subjects conducted tasks that matched the BIS interface while the other group of subjects performed tasks that didn't match the BIS interface. The extent of regulatory compatibility was represented by the interaction between the BIS interface and the subjects' style of processing. Due to the rich visualization of the BIS interface, subjects who achieved higher score on visual style of processing were expected to experience high regulatory compatibility, whereas subjects who obtained lower score were expected to experience low regulatory compatibility. 
Intention to explore, variables related to engagement experience, and subjects' demographic data were measured in the experiment. Measurement items for visual style of processing were adapted from Childers et al. [16]. A sample item would be "I enjoy doing work that requires the use of pictures". Items for intention to explore BIS were adapted from Maruping and Magni [56] and Nambisan et al. [58] for our investigative context. A sample item would be "I intend to spend time and effort in exploring BIS functions for potential applications in my work". Items for perceived aesthetics were adapted from Lavie and Tractinsky [51]. A sample item would be "The interface of business intelligence system is clear". Items for perceived enjoyment were adapted from Agarwal and Karahanna [1], and a sample item would be "Conducting tasks with business intelligence system was enjoyable". Items for cognitive effort were adapted from Hong et al. [33], and a sample item would be "It takes much effort to use the BIS to complete the task".

The experiment was conducted in a computer lab with ten seats. Because of the room-size limitation, the experiment was divided into multiple sessions. Each session was administrated by the same experimenters, and followed the standardized protocol. The experimental procedures were as follows.

Step 1: Subjects firstly conducted a survey on lab computers to rate their style of processing and demographics.

Step 2: A cover story was provided for the subjects. A good cover story can strengthen the influence of experimental manipulation, and offer rational for data collection [29]. From the cover story, subjects learned that they would use the BIS in the experiment and they would act as system analysts. A video clip was briefly displayed to introduce the BIS interface to alleviate the novelty effect of BIS, if any. Therefore, subjects had a preliminary understanding of the essential functions of BIS when performing the tasks.

Step 3: The lab computer randomly assigned a type of treatment to the subject. Randomization of treatment assignments serves to control for possible confounding effects. This experiment ensured that a similar number of subjects were assigned to each treatment. One group of subjects was assigned to the low cognitive fit group, whereas the other group was assigned to the high cognitive fit group. Both groups used the same BIS interface to ensure that they received the same information from the interface.

Step 4: After completing the task, the subjects answered the questions of manipulation check on cognitive fit. They also assessed survey questions about their perceived aesthetics, perceived enjoyment, cognitive effort and intention to explore BIS.

\section{Results}

There were 325 subjects recruited from 8 academic faculties, representing diverse backgrounds. Among the student subjects, 94 (28.9\%) were males and $231(71.1 \%)$ were females. The average age of the participants was 21.3. There was no significant difference in gender and age distribution across the experimental conditions. We categorized subjects' scores on visual style of processing using median split approach. Subjects who achieved higher scores were regarded as experiencing high regulatory compatibility, while subjects who obtained lower scores were viewed as experiencing low regulatory compatibility.

ANOVA was conducted on perceived aesthetics, cognitive effort and perceived enjoyment (see Table 1, Table 2, and Table 3, respectively). ANOVA results on perceived aesthetics suggest that cognitive fit and regulatory compatibility significantly affected perceived aesthetics $(p<.05)$. T-test results on the effect of cognitive fit on perceived aesthetics suggest that subjects who experienced a high cognitive fit displayed significantly higher perceived aesthetics ( $\mathrm{p}$ $<.05$ ), as compared to subjects who experienced a low cognitive fit, thus supporting H1. T-test results on the effect of regulatory compatibility on perceived aesthetics suggest that subjects who experienced a high regulatory compatibility displayed significantly higher perceived aesthetics toward BIS ( $\mathrm{p}<.05)$, as compared to subjects who experienced a low regulatory compatibility, thus supporting $\mathrm{H} 7$.

ANOVA results on cognitive effort suggest that cognitive fit significantly affected perceived aesthetics $(\mathrm{p}<.05)$, while regulatory compatibility had marginally significant effect on cognitive effort. T-test results on the effect of cognitive fit on cognitive effort suggest that subjects who experienced a high cognitive fit displayed significantly lower cognitive effort $(\mathrm{p}<.05)$, as compared to subjects who experienced a low cognitive fit, thus supporting $\mathrm{H} 3$.

ANOVA results on perceived enjoyment suggest that cognitive fit and regulatory compatibility significantly affected perceived enjoyment $(\mathrm{p}<.05)$. T-test results on the effect of cognitive fit on perceived enjoyment suggest that subjects who experienced a high cognitive fit display significantly higher perceived enjoyment $(\mathrm{p}<.05)$, as compared to subjects who experienced a low cognitive fit, thus supporting H5. T-test results on the effect of regulatory compatibility on perceived enjoyment suggest that subjects who experienced a high 
regulatory compatibility display significantly higher perceived enjoyment toward BIS $(p<.05)$, as compared to subjects who experienced a low regulatory compatibility, thus supporting $\mathrm{H} 8$.

Table 1. ANOVA summary table on perceived aesthetics

\begin{tabular}{|l|l|l|l|l|}
\hline Source & df & $\begin{array}{l}\text { Mean } \\
\text { Square }\end{array}$ & F & Sig. \\
\hline Cognitive fit & 1 & 8.41 & 8.674 & 0.00 \\
\hline $\begin{array}{l}\text { Regulatory } \\
\text { compatibility }\end{array}$ & 1 & 15.01 & 15.48 & 0.00 \\
\hline
\end{tabular}

Table 2. ANOVA summary table on cognitive effort

\begin{tabular}{|l|l|l|l|l|}
\hline Source & df & $\begin{array}{l}\text { Mean } \\
\text { Square }\end{array}$ & F & Sig. \\
\hline Cognitive fit & 1 & 106.97 & 77.44 & 0.00 \\
\hline $\begin{array}{l}\text { Regulatory } \\
\text { compatibility }\end{array}$ & 1 & 4.96 & 3.59 & 0.06 \\
\hline
\end{tabular}

Table 3. ANOVA summary table on perceived enjoyment

\begin{tabular}{|l|l|l|l|l|}
\hline Source & df & $\begin{array}{l}\text { Mean } \\
\text { Square }\end{array}$ & F & Sig. \\
\hline Cognitive fit & 1 & 17.22 & 13.42 & 0.00 \\
\hline $\begin{array}{l}\text { Regulatory } \\
\text { compatibility }\end{array}$ & 1 & 18.07 & 14.08 & 0.00 \\
\hline
\end{tabular}

Amos 21.0 was used to test the structural model proposed on the right side of figure 1 . The measurement model was assessed by examining the construct reliability and construct validity. Data in table 4 showed that the measurement model obtained acceptable internal consistency, since both Cronbach's alpha and composite reliability surpassed the threshold of 0.707. The measurement model also satisfied the requirement of convergent validity, since all AVEs exceeded the threshold of 0.5 [28]. The measurement model achieved acceptable discriminant validity, since the square roots of AVEs exceeded all correlation coefficients [42], as can be seen in table 5. Additionally, the confirmatory factor analysis (CFA) results showed that the measurement model achieved good model fit $(\chi 2 /$ d.f. $=2.38, \mathrm{p}<$ $0.001, \mathrm{CFI}=0.976, \mathrm{GFI}=0.937, \mathrm{RMSEA}=0.065)$. The above results collectively suggest appropriate measurement properties.

Table 4. Cronbach's alpha and composite reliability

\begin{tabular}{|l|l|l|}
\hline Constructs & $\begin{array}{l}\text { Cronbach's } \\
\text { alpha }\end{array}$ & $\begin{array}{l}\text { Composite } \\
\text { reliability }\end{array}$ \\
\hline
\end{tabular}

\begin{tabular}{|l|l|l|}
\hline Intention to explore & 0.92 & 0.92 \\
\hline $\begin{array}{l}\text { Perceived } \\
\text { enjoyment }\end{array}$ & 0.92 & 0.92 \\
\hline Perceived aesthetics & 0.87 & 0.87 \\
\hline Cognitive effort & 0.89 & 0.93 \\
\hline
\end{tabular}

Table 5. Construct correlation

\begin{tabular}{|c|l|l|c|c|}
\hline Construct & \multicolumn{1}{c|}{ ITE } & \multicolumn{1}{c|}{ PE } & PA & CE \\
\hline ITE & 0.88 & & & \\
\hline PE & 0.457 & 0.89 & & \\
\hline PA & 0.480 & 0.498 & 0.83 & \\
\hline CE & -0.316 & -0.293 & -0.379 & 0.88 \\
\hline Note: 1) ITE $=$ Intention to explore \\
PE $=$ Perceived enjoyment \\
PA $=$ Perceived aesthetics \\
CE $=$ Cognitive effort
\end{tabular}
AVE.

Next, we examined the path coefficients and their significance levels through structure equation modeling. Results in figure 2 suggest that perceived aesthetics and perceived enjoyment display significant and positive effect on intention to explore, while cognitive effort displays significant but negative effect on intention to explore. Thus, H2, 4, and 6 are supported.

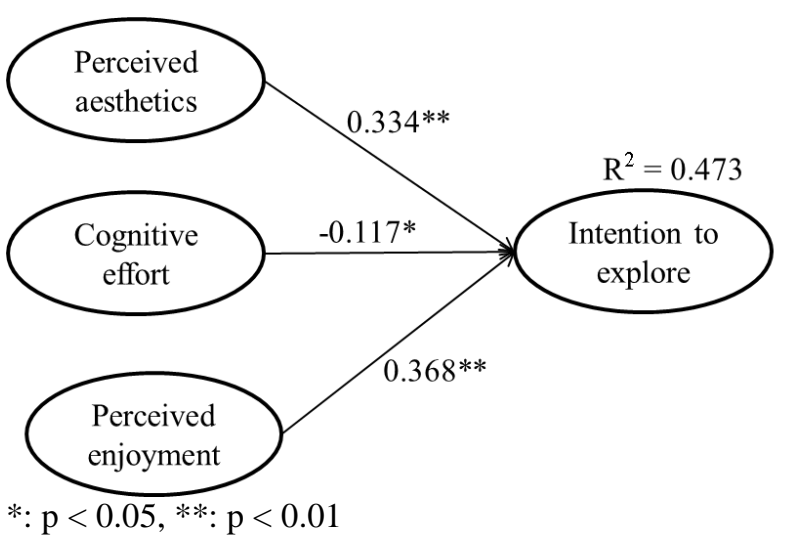

Figure 2. Structural equation modeling

\section{Discussion and Study Limitations}

Our results provide several insights about the antecedents of intention to explore BIS. To the best of our knowledge, this is among the first in IS research that investigates the impact of engagement experience on users' intention to explore BIS. Our results showed that perceived aesthetics and perceived enjoyment were both positively associated with users' intention to explore BIS, while cognitive 
effort was negatively associated with users' intention to explore BIS. When users are more engaged with the BIS, they may be more willing to explore BIS. Next, this study further examines antecedents of engagement experience from the fit perspective. Our results showed that cognitive fit influenced perceived aesthetics, perceived enjoyment and cognitive effort. Specifically, when users experienced a high cognitive fit, they displayed higher perceived aesthetics and enjoyment but consumed lower cognitive effort. Our results also showed that the regulatory compatibility between BIS interface and users' style of processing could influence their perceived aesthetics and enjoyment. When users experienced a high regulatory compatibility, they displayed higher perceived aesthetics and enjoyment toward the BIS.

While this study was conducted in the context of BIS, scholars could examine the generalizability of our findings in other technological settings where the visual design of interfaces may have significant impacts on user performance. In addition, as we tested our model with student participants, we recommend future research testing our model with managers or professionals such as data analysts and data scientists, whose works involve rich data visualization at work.

\section{Conclusion}

This study investigates the effect of engagement experience on users' intention to explore BIS functions. Users' intention to explore BIS functions is a crucial predictor for BIS exploration behavior which can lead to successful system implementation and realization of organizational business value [56, 58]. In general, this research offers several major theoretical contributions. Firstly, prior research on exploration intentions has called for research to examine antecedents that promote its development [e.g., 55, 56, 58]. This study suggests that the engagement experience can influence users' intention to explore BIS functions. Next, this study further examines antecedents of engagement experience from the perspective of cognitive fit and regulatory compatibility. To our knowledge, this is first study that introduces regulatory compatibility into IS context and links the regulatory compatibility to engagement experience. This study suggests that both cognitive fit and regulatory compatibility could contribute to users' engagement experience. Finally, this study responds to the call for investigating BIS related issues [e.g., 15]. The empirical studies on BIS use have received limited attention [e.g., 15]. This study has critical implications concerning the direction of BIS implementation and BIS user experience.

Regarding potential practical implications, this study implies that organizations that implement BIS could enhance users' engagement experience to promote their explorative intention, which in turn may lead to actual exploration behaviors. For BIS designers, they may consider the fit between BIS interface and tasks users perform in their work. They may also take into account users' personal characteristics, such as their style of information processing, to ensure compatibility between the BIS interface and users' personal factors.

\section{References}

[1] Agarwal, R., and Karahanna, E. 2000. "Time Flies When You're Having Fun: Cognitive Absorption and Beliefs about Information Technology Usage," MIS Quarterly (24:4), pp. 665-694.

[2] Ahuja, M. K., and Thatcher, J. B. 2005. "Moving Beyond Intentions and Toward the Theory of Trying: Effects of Work Environment and Gender on Post-adoption Information Technology Use," MIS Quarterly (29:3), pp. 427-459.

[3] Avnet, T., and Higgins, E. T. 2006. "How Regulatory Fit Affects Value in Consumer Choices and Opinions," Journal of Marketing Research (43:1), pp. 1-10.

[4] Bakker, A. B., and Demerouti, E. 2008. "Towards A Model of Work Engagement," Career Development International (13:3), pp. 209-223.

[5] Bakker, A.B., and Leiter, M.P. (Eds.) 2010. Work engagement: A handbook of essential theory and research, New York, NY: Psychology Press.

[6] Bakker, A. B., Schaufeli, W. B., Leiter, M. P., and Taris, T. W. 2008. "Work Engagement: An Emerging Concept in Occupational Health Psychology," Work \& Stress (22:3), pp. 187-200.

[7] Beardsely, M. 1982. The Aesthetic Point of View. Ithaca, NY: Cornell University Press.

[8] Bloomberg Businessweek. 2011. "The Current State of Business Analytics: Where Do We Go from Here?," Bloomberg Business-week Research Services (http://www.sas.com/resources/asset/

busanalyticsstudy_wp_08232011.pdf).

[9] Bracht, G. H., and Glass, G. V. 1968. "The External Validity of Experiments," American Educational Research Journal (5:4), pp. 437-474.

[10] Brief, A. P., and Aldag, R. J. 1977. "The Intrinsicextrinsic Dichotomy: Toward Conceptual Clarity," Academy of Management Review (2:3), pp. 496500.

[11] Brkich, M., Jeffs, D., and Carless, S. A. 2002. "A Global Self-report Measure of Person-job Fit," European Journal of Psychological Assessment (18:1), p. 43-51.

[12] Brown, S. A., and Venkatesh, V. 2005. "Model of Adoption of Technology in Households: A Baseline Model Test and Extension Incorporating Household Life Cycle,” MIS Quarterly (29:3), pp. 399-426. 
[13] Cable, D. M., and DeRue, D. S. 2002. "The Convergent and Discriminant Validity of Subjective Fit Perceptions," Journal of Applied Psychology (87:5), pp. 875-884.

[14] Cable, D. M., and Judge, T. A. 1996. "Personorganization Fit, Job Choice Decisions, and Organizational Entry," Organizational Behavior and Human Decision Processes (67:3), pp. 294-311.

[15] Chen, H., Chiang, R. H., and Storey, V. C. 2012. "Business Intelligence and Analytics: From Big Data to Big Impact," MIS Quarterly (36:4), pp. 1165-1188.

[16] Childers, T. L., Houston, M. J., and Heckler, S. E. 1985. "Measurement of Individual Differences in Visual versus Verbal Information Processing," Journal of Consumer Research (12:2), pp. 125-134.

[17] Davenport T. H., Harris J. G., andMorison R. 2010. Analytics at Work: Smarter Decisions, Better Results, Harvard Business School Publishing Corporation, Boston.

[18] Davis, F. D., Bagozzi, R. P., and Warshaw, P. R. 1992. "Extrinsic and Intrinsic Motivation to Use Computers in the Workplace," Journal of Applied Social Psychology (22:14), pp. 1111-1132.

[19] Deci, E. L. Intrinsic Motivation, Plenum, New York, 1975.

[20] Deng, X., and Chi, L. 2012. "Understanding Postadoptive Behaviors in Information Systems Use: A Longitudinal Analysis of System Use Problems in the Business Intelligence Context," Journal of Management Information Systems (29:3), pp. 291-326.

[21] Deng, L., and Poole, M. S. 2010. "Affect in Web Interfaces: A Study of the Impacts of Web Page Visual Complexity and Order," MIS Quarterly (34:4), pp. 711-730. [22] Fishwick P. A. 2002. "Aesthetic Programming: Crafting Personalized Software," Leonardo (35:4), pp. 383-390.

[23] Forster, J., Grant, H., Idson, C. L., and Higgins, E. T. 2001. "Effects of Success and Failure on Motivational Strength: Regulatory Focus as Moderator," Journal of Experimental Social Psychology (37:3), pp. 253-260.

[24] Fredrickson, B. L. 2001. "The Role of Positive Emotions in Positive Psychology: The Broaden-and-build Theory of Positive Emotions," American psychologist (56:3), pp. 218-226.

[25] Garbarino, E. C., and Edell, J. A. 1997. "Cognitive Effort, Affect, and Choice," Journal of Consumer Research (24:2), pp. 147-158.

[26] Gartner 2009. Gartner Identifies the Top 10 Strategic Technologies for 2010. Report, http://www.gartner.com/it/ page.jsp?idD1210613.

[27] Gruman, J. A., and Saks, A. M. 2011. "Performance Management and Employee eEngagement,"Human Resource Management Review (21:2), pp. 123-136.

[28] Hair, J. F., Tatham, R. L., Anderson, R. E., and Black, W. 2006. Multivariate data analysis, (Pearson Prentice Hall Upper Saddle River, NJ.

[29] Harmon-Jones, E., Amodio, D. M., and Zinner, L. R. 2007. Social Psychological Methods of Emotion Elicitation, Handbook of emotion elicitation and assessment, pp. 91-105.
[30] Harris, L., and Dennis, C. 2011. "Engaging Customers on Facebook: Challenges for E-retailers," Journal of Consumer Behavior (10:6), pp. 338-346.

[31] Hassenzahl, M., and Tractinsky, N. 2006. "User Experience-A Research Agenda," Behavior \& information technology (25:2), pp. 91-97.

[32] Hirschman, E. C. 1980. "Innovativeness, Novelty Seeking, and Consumer Creativity," Journal of consumer research (7:3), pp. 283-295.

[33] Hong, W., Thong, J. Y., and Tam, K. Y. 2004. "The Effects of Information Format and Shopping Task on Consumers' Online Shopping Behavior: A Cognitive Fit Perspective," Journal of Management Information Systems (21:3), pp. 149-184.

[34] Hsieh, J. P. A., Rai, A., and Keil, M. 2008. "Understanding Digital Inequality: Comparing Continued Use Behavioral Models of the Socio-economically Advantaged and Disadvantaged," MIS Quarterly (32:1), pp. 97-126.

[35] Isen, A. M., and Daubman, K. A. 1984. "The Influence of Affect on Categorization," Journal of Personality and Social Psychology (47:6), pp. 1206-1217.

[36] Isen, A. M., Daubman, K. A., and Nowicki, G. P. 1987. "Positive Affect Facilitates Creative Problem Solving," Journal of Personality and Social Psychology," Journal of Personality and Social Psychology (52:6), pp. 1122-1131.

[37] Isen, A. M., and Means, B. 1983. "The Influence of Positive Affect on Decision-making Strategy," Social cognition (2:1), pp. 18-31.

[38] Isen, A. M., Rosenzweig, A. S., and Young, M. J. 1991. "The Influence of Positive Affect on Clinical Problem Solving," Medical Decision Making (11:3), pp. 221-227.

[39] Jacques, R., Preece, J., and Carey, T. 1995. "Engagement as A Design Concept for Multimedia," Canadian Journal of Educational Communication (24:1), pp. 49-59.

[40] Jasperson, J. S., Carter, P. E., and Zmud, R. W. 2005. "A Comprehensive Conceptualization of Post-adoptive Behaviors Associated with Information Technology Enabled Work Systems," MIS Quarterly (29:3), pp. 525557.

[41] Jarvenpaa, S. L., and Todd, P. A. 1997. "Is There A Future for Retailing on the Internet," Electronic Marketing and the Consumer (1:12), pp. 139-154.

[42] John, O. P., and Benet-Martinez, V. 2000. "Measurement: Reliability, construct validation, and scale construction," Handbook of Research Methods in Social and Personality Psychology. Cambridge, UK: Cambridge University Personality.

[43] Kahneman, D. 1973. Attention and Effort, Englewood Cliffs, NJ: Prentice-Hall.

[44] Kamis, A., Koufaris, M., and Stern, T. 2008. "Using an Attribute-based Decision Support System for Usercustomized Products Online: An Experimental Investigation,” MIS Quarterly (32:1), pp. 159-177.

[45] Karvonen, K. 2000. "The Beauty of Simplicity," in Proceedings on the 2000 ACM conference on Universal Usability, pp. 85-90. 
[46] Kashdan, T. B., Rose, P., and Fincham, F. D. 2004. "Curiosity and Exploration: Facilitating Positive Subjective Experiences and Personal Growth Opportunities," Journal of Personality Assessment (82:3), pp. 291-305.

[47] Keller, J., and Bless, H. 2008. "Flow and Regulatory Compatibility: An Experimental Approach to the Flow Model of Intrinsic Motivation," Personality and Social Psychology Bulletin (34:2), pp 196-209.

[48] Ko, D. G., Kirsch, L. J., and King, W. R. 2005. "Antecedents of Knowledge Transfer from Consultants to Clients in Enterprise System Implementations," MIS Quarterly (29:1), pp. 59-85.

[49] Koufaris, M. 2002. "Applying the Technology Acceptance Model and Flow Theory to Online Consumer Behavior," Information Systems Research (13:2), pp. 205 223.

[50] Laurel, B. 2013. Computers as Theatre, AddisonWesley.

[51] Lavie, T., and Tractinsky, N. 2004. "Assessing Dimensions of Perceived Visual Aesthetics of Web Sites," International Journal of Human-Computer Studies (60:3), pp. 269-298.

[52] Lee, Y., Chen, A. N., and Ilie, V. 2012. "Can Online Wait Be Managed? The Effect of Filler Interfaces and Presentation Modes on Perceived Waiting Time Online," MIS Quarterly 36(2), pp. 365-394.

[53] Li, X., Hsieh, J. P.-A., and Rai, A. 2013. "Motivational Differences Across Post-Acceptance Information System Usage Behaviors: An Investigation in the Business Intelligence Systems Context," Information Systems Research (24:3), pp. 659-682.

[54] Lyubomirsky, S., King, L., and Diener, E. 2005. "The Benefits of Frequent Positive Affect: Does Happiness Lead to Success," Psychological Bulletin (131:6), pp. 803-855.

[55] Magni, M., Taylor, M. S., and Venkatesh, V. 2010. “"To Play or Not to Play': A Cross-Temporal Investigation Using Hedonic and Instrumental Perspectives to Explain User Intentions to Explore a Technology," International Journal of Human-Computer Studies (68), pp. 572-588.

[56] Maruping, L. M., and Magni, M. 2015. "Motivating Employees to Explore Collaboration Technology in Team Contexts," MIS Quarterly (39:1), pp. 1-16.

[57] Nakamura, J., and Csikszentmihalyi, M. 2009. Flow Theory and Research, Handbook of Positive Psychology, pp. 195-206.

[58] Nambisan, S., Agarwal, R., and Tanniru, M. 1999. "Organizational Mechanisms for Enhancing User Innovation in Information Technology," MIS Quarterly (23:3), pp. 365-395.

[59] Negash, S., and Gray, P. 2008. Business Intelligence, Springer Berlin Heidelberg.

[60] O'Brien, H. L., and Toms, E. G. 2008. "What is User Engagement? A Conceptual Framework for Defining User Engagement with Technology," Journal of the American Society for Information Science and Technology (59:6), pp. 938-955.

[61] Overbeeke, K., Djajadiningrat, T., Hummels, C., Wensveen, S., and Prens, J. 2003. Let's Make Things Engaging, in Funology, Springer Netherlands, pp. 7-17.

[62] Payne, J. W. 1982. "Contingent Decision Behavior,” Psychological Bulletin (92:2), pp. 382-402.
[63] Pereira, R.E. 2000. "Optimizing Human-computer Interaction for the Electronic Commerce Environment," Journal of Electnmic Commerce Research (1:1), pp. 23-44. [64] Ramanathan, S., and Dhar, S. K. 2010. "The Effect of Sales Promotions on the Size and Composition of the Shopping Basket: Regulatory Compatibility from Framing and Temporal Restrictions," Journal of Marketing Research (47:3), pp. 542-552.

[65] Rogers, E.M. 2003. Diffusion of Innovations (5th ed.). New York: Free Press.

[66] Rud, Olivia 2009. Business Intelligence Success Factors: Tools for Aligning Your Business in the Global Economy, Hoboken, N.J: Wiley \& Sons.

[67] Russo, J. E., and Dosher, B. A. 1983. "Strategies for Multiattribute Binary Choice," Journal of Experimental Psychology: Learning, Memory, and Cognition (9:4), pp. 676-696.

[68] Saga V. L., and Zmud, R. W. 1994. "The Nature and Determinants of IT Acceptance, Routinization, and Infusion," in Diffusion, Transfer and Implementation of Information Technology (LEVINE L, Ed.), North-Holland, Amsterdam pp, pp. 67-86,

[69] Salvo, M.J. 2002. "Critical Engagement with Technology in the Computer Classroom," Technical Communication Quarterly (11:3), pp. 317-337.

[70] Shah, S. K. 2006. "Motivation, Governance, and the Viability of Hybrid Forms in Open Source Software Development," Management Science (52:7), pp. 1000-1014. [71] Sousa, R., and Goodhue, D. 2003. "Understanding Exploratory Use of ERP Systems," in AMCIS Proceedings. [72] Speier, C., and Morris, M. G. 2003. "The Influence of Query Interface Design on Decision-making Performance," MIS Quarterly (27:3), pp 397-423.

[73] Todd, P., and Benbasat, I. (1999). "Evaluating the Impact of DSS, Cognitive Effort, and Incentives on Strategy Selection," Information Systems Research (10:4), pp. 356-374.

[74] Tung, W., Moore, R., and Engelland B. 2006. "Exploring Attitudes and Purchase Intentions in a Brandoriented, Highly Interactive Web Site Setting," Marketing Management Journal (16:2), pp. 94-106.

[75] Venkatesh, V. 1999. "Creation of Favorable User Perceptions: Exploring the Role of Intrinsic Motivation," MIS quarterly (23:2), pp. 239-260.

[76] Venkatesh, V. 2000. "Determinants of Perceived Ease of Use: Integrating Control, Intrinsic Motivation, and Emotion into the Technology Acceptance Model," Information systems research (11:4), pp. 342-365.

[77] Vessey, I. 1991. "Cognitive Fit: A Theory-Based Analysis of the Graphs Versus Tables Literature," Decision Sciences (22:2), pp. 219-240.

[78] Wasko, M. M., and Faraj, S. 2005. "Why Should I Share? Examining Social Capital and Knowledge Contribution in Electronic Networks of Practice," MIS Quarterly (29:1), pp. 35-57.

[79] Zhao, G., and Pechmann, C. 2007. "The Impact of Regulatory Focus on Adolescents' Response to Antismoking Advertising Campaigns," Journal of Marketing Research (44:4), pp. 671-687. 